Centenário de nascimento de
Celso Furtado (1920-2004) 


\title{
Celso Furtado: um economista com lentes de literato
}

\author{
ELISA KLÜGER ${ }^{I}$
}

\section{Introdução $^{1}$}

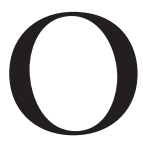

CENTENÁRIO do economista e intelectual brasileiro Celso Furtado (1920-2004) convida-nos a refletir sobre a importância de seu pensamento nos dias de hoje. Múltiplas seriam as maneiras de discorrer acerca de seu legado. Celso Furtado produziu reconhecida obra como historiador econômico do Brasil, teve reconhecimento internacional como acadêmico, com livros traduzidos para uma dezena de línguas e convites para atuar como professor/pesquisador em universidades de prestígio como Cambridge, Yale e Sorbonne. Seria possível, por exemplo, discutir a atualidade da sua visão sobre os problemas do Nordeste do Brasil, da reflexão que conduz sobre a necessidade de planejamento econômico para o desenvolvimento, do seu entendimento relativo à especificidade histórica e social da conformação das economias subdesenvolvidas, dentre tantos tópicos fecundos de sua produção.

Outro caminho para versar sobre a importância de Furtado seria glosar acerca de sua atuação como intelectual público e homem político de destaque. Celso Furtado ocupou funções de direção no Banco Nacional de Desenvolvimento Econômico (BNDE), liderou a criação e dirigiu a Superintendência de Desenvolvimento do Nordeste (Sudene), foi embaixador do Brasil junto à Comunidade Econômica Europeia e exerceu a função de ministro do Planejamento e de ministro da Cultura. No caso, caberia tematizar, por exemplo, os desafios por ele enfrentados para contrapor-se a segmentos do poder político e econômico que contrariavam os projetos de desenvolvimento. Seria possível, igualmente, tratar da batalha que, em consonância com as teses da Comissão Econômica para a América Latina (Cepal), travou pela industrialização planejada como alternativa à dependência do setor agroexportador. No caso da atuação pública, a Obra autobiográfica de Furtado (2014) e seus Diários intermitentes 1937-2002 (Furtado, 2019) oferecem vasto material para meditar acerca da tenacidade com a qual se esforçou, sucessivamente, por promover transformações sociais e econômicas que impelissem o país em direção inclusiva e igualitária.

Este ensaio trata de uma face menos visível do legado de Celso Furtado, ao partir da discussão de sua relação com a literatura em sua biografia e da análise de um de seus projetos de romance para captar qual era a visão das estruturas da sociedade brasileira subjacente à sua contribuição intelectual e atuação pública como economista. Menos visível tanto por tratar-se de uma temática relativa 
à formação do olhar que cultivou como economista quanto por basear-se, fundamentalmente, em anotações pessoais disponibilizadas apenas em 2019, nos Diários intermitentes.

Os Diários incluem três projetos inacabados de romance. O primeiro data de 1944, o segundo, de 1955, e o terceiro, de 1975. Neste ensaio, optou-se por analisar em detalhe o esboço de 1955, que é o mais completo e o que mais dialoga com as interpretações de Furtado sobre o Brasil. Esse é posterior ao doutorado em Economia cursado por Furtado na Sorbonne entre 1946 e 1948 $\mathrm{e}$ às incursões no estudo das ciências sociais que datam da mesma época. No período em que delineou o romance, Furtado atuava como economista na Cepal e acabava de concluir uma missão de dois anos como consultor cedido pela Comissão ao BNDE. Na ocasião, coube a ele esboçar um plano de desenvolvimento sistemático para o país, tarefa que lhe convidou a aprofundar sua leitura sobre as particularidades da estrutura econômica e social brasileira.

O projeto de romance de 1955 cerze uma narrativa de cunho realista, calcada na descrição de tensões sociais entre personagens nordestinas que são arquétipos de classes sociais distintas. A história teria início em 1930, relatando a inflamação das relações sociais no contexto do assassinato do então governador da Paraíba, João Pessoa Cavalcanti de Albuquerque. O esmiuçar do rascunho permite captar quais características da sociedade brasileira eram enfatizadas por Furtado e detectar sua sensibilidade para enredos povoados por indivíduos que em nada se aproximam do homo aconomicus da teoria econômica neoclássica, ${ }^{2}$ ou seja, indivíduos que não são abstratos, isolados, racionais e dotados de um conjunto dado de preferências. Bem como ressaltar sua capacidade de projetar cenários conformados por estruturas sociais, culturais e de poder que enquadram as ações destes indivíduos. O cotejamento da narrativa com a biografia de Celso Furtado revela, ademais, que o romance se inspirava em acontecimentos que marcaram a vida do próprio autor e influenciaram seu entendimento sobre o Brasil.

Este ensaio mobilizará, de forma paralela, fontes biográficas, o esboço de romance e trechos de escritos autobiográficos e entrevistas nos quais Furtado versa sobre a sua relação com a literatura e sobre a intenção de tornar-se romancista. $\mathrm{O}$ texto que se segue à introdução está divido em três seções seguidas de uma conclusão. A primeira seção tematiza a sua relação com a literatura; a segunda detém-se sobre projeto de romance de 1955; e a terceira discute a afinidade do olhar literário com a sua forma de ler a economia e sociedade brasileira. O ensaio não objetiva, portanto, fazer uma análise literária do esboço de romance, mas tomá-lo como ponto de observação privilegiado para apreender a imaginação sociológica e a matriz de interpretação da sociedade brasileira que fizeram de Furtado um economista inexoravelmente heterodoxo.

\section{Os flertes com a literatura e os aportes da ciência}

Celso Furtado conta que Eugênio Gudin " "me disse um dia, em tom de reprimenda: 'Você apela demasiadamente para a imaginação em suas análises. 
Devia ter sido romancista, e não economista'. Não cabe dúvida de que a imaginação descontrolada produz delírios, mas como conceber uma construção teórica sem um forte ingrediente de imaginação?” (Furtado, 2014, p.89). É possível sustentar que a recriminação de Gudin teria sido tomada como um elogio por Furtado, já que ele sustentava que ficção (e não a ciência) oferecia as melhores ferramentas para pintar o homem. Furtado argumentava também que apenas a imaginação e a reinvenção permitiam captar as particularidades dos processos históricos. Assim, para pensar a sociedade era preciso primeiro imaginá-la e inventá-la, para depois formular hipóteses globais e analisá-la (Furtado, 1992; $2012 ; 2014)$. Sobretudo, é possível crer que Furtado teria apreciado o comentário de Gudin posto que flertara com a ideia de se tornar escritor durante décadas.

A paixão de Celso pela leitura foi precoce. Seu pai, Maurício de Medeiros Furtado, era membro de uma família de magistrados e, como seus antepassados, foi advogado, juiz e desembargador. Além de ter uma vasta biblioteca, que foi determinante no despertar do gosto de Celso pela literatura, Maurício Furtado cultivara a escrita ${ }^{4}$ em paralelo à advocacia (Furtado, 2013, p.32-3). Segundo Rosa Freire d'Aguiar, ${ }^{5}$ ele escrevia textos jornalísticos para periódicos, discorria sobre temas clássicos do direito e tinha escritos sobre o folclore local, com destaque para as danças religiosas compostas pelos cordões azul e encarnado, ${ }^{6}$ que teria registrado detalhadamente. Ele chegou também a ser eleito membro do Instituto Histórico e Geográfico Paraibano e da Academia Paraibana de Letras. O exemplo paterno permitia, assim, que Celso Furtado vislumbrasse ser possível conciliar o amor pela literatura com as obrigações de magistrado e funcionário público; caminho tradicional de uma geração de escritores que garantia seus rendimentos ao atuar no funcionalismo e política e, de forma paralela, conduzia carreiras literárias (Miceli, 2001; Guimarães, 2017).

Celso Furtado (2013, p.33) comenta que, no "curso secundário, a nenhuma matéria dediquei tanto tempo como ao latim [que...] se me afigurava como a chave que me permitiria o acesso a uma cultura superior. Progressivamente, fui me fixando na literatura, particularmente no estudo de autores de língua portuguesa". Furtado começou a sua vida de escritor (e de assalariado) pelo jornalismo. Aos 17 anos, colaborava com jornais estudantis de João Pessoa e, ao instalar-se no Rio de Janeiro para cursar a Faculdade de Direito, passou a escrever sistematicamente na Revista da Semana e atuar como revisor no Correio da Manhã. Pouco depois, começaria a escrever também para $O$ Panfleto e para o Observador Econômico e Financeiro (Furtado, 2014; 2019).

Furtado detalha que o trabalho como jornalista se afigurava como uma maneira de observar o mundo e parecia ser uma forma de ganhar a vida consequente com o seu desejo de escrever. Até os 30 anos, ele achava que seria escritor e considerava que a sua "forma de expressão natural seria a ficção literária". Seu primeiro livro, De Nápoles a Paris: contos da vida expedicionária (1946) redigido aos 25 anos e baseado nas vivências como integrante da Força Expedicionária Brasileira durante a Segunda Guerra Mundial - foi, entretanto, a única 
obra ficcional que publicou (Furtado, 2013; 1992). Se Furtado não se tornou romancista, ele jamais deixou de ser escritor, tendo publicado uma trintena de livros ao longo da vida, majoritariamente em áreas conexas a história, política e economia, além dos contos e de relatos autobiográficos.

A inflexão em direção à carreira científica, argumenta, teria sido motivada pela percepção de que, para compreender o mundo que observava como jornalista, seria "preciso me armar com instrumentos muito mais completos", pois "não bastava olhar para ele, testemunhar [...]. Foi aí que me veio a ideia de estudar Economia" (Furtado, 1992). Em paralelo, a atuação como funcionário do Departamento Administrativo do Serviço Público (Dasp) fomentou o interesse pela organização da administração estatal e incitou o redirecionamento para o estudo dos problemas sociais e econômicos. Os mergulhos nas ciências sociais não eram, no entanto, novos, já que Furtado havia lido autores como Gilberto Freyre, Karl Marx e Karl Mannheim. Bem como explorado, de maneira autodidata, a economia, que jugava ser "um instrumento para penetrar no social e no político, e avançar na compreensão da história” (Furtado, 2014, p.27; 2013).

A publicação dos Diários intermitentes (Furtado, 2019) permite afirmar que, malgrado o desvio em direção à formação científica e à escrita não ficcional, a ideia de escrever um romance foi repetidamente cogitada e praticada ao longo da vida de Furtado. Neles, revelam-se predileções, ${ }^{7}$ meditações e hesitações quanto ao exercício de atividade literária e estão disponíveis três esboços de romances, com distância de três décadas, demostrando a persistência do desejo de ser novelista. O primeiro esboço de romance disponível nos Diários data de maio de 1944, momento em que o autor vivia no Rio de Janeiro. Batizado de Transumância, o romance versaria sobre o processo de adaptação à metrópole de personagens provenientes do interior e contraporia trajetos de integração social diversos com consequências díspares. O projeto é delineado da seguinte maneira:

A figura A tem uma vida de grupo até a vinda para a metrópole. Representará a tentação do homem de classe média em face das facilidades, riquezas e valores da alta sociedade. Será o mundo artístico o canal por onde ele deslizará. A sua libertação final será através do amor puro à arte individualista. A figura B terá uma vida de facilidades - remanescência da velha família - antes de vir para a metrópole. Nesta será tragado pelas formas mais desregradas de vida. Será a experiência do sensualista. Sua libertação será através do misticismo - sem religião -, somente a fé em atingir o sublime nesta vida. A figura $\mathrm{C}$ representará a vida do retraído, do intelectual individualista, do homem nietzschiano - durante a primeira fase de sua vida. Com a vinda para a metrópole haverá nele uma involução no conceito dos valores individualistas. Ele se libertará entregando-se a um grupo, através de uma ampliação cósmica de seus mitos. [...]. O delineamento das figuras será tentado através do pensamento de cada uma. Será concentrado grande interesse em torno de diálogos (ilustrados subjetivamente) onde serão debatidas ideias que concorrerão para definir personalidades. (Furtado, 2019, p.66-7) 
Ao plano relativo à formação das personagens segue-se uma série de reflexões sobre a sua atividade com romancista, sobre o planejamento da escrita e sobre a técnica literária que deveria adotar, ressaltando a influência de André Malraux e Marcel Proust. Segundo Furtado, as personagens seriam construídas entre suas meditações subjetivas e por meio do contraste da expressão de cada um dos tipos quando engajados em diálogos. O projeto inspira-se, certamente, na própria experiência de Furtado de translado para a metrópole e nos choques que experimentou no período. Constam em seus registros da época comentários sobre o contato que teve no Rio de Janeiro com

[...] a sordidez moral, a degenerescência, a perversão do homem. Não a vi, mas dela tomei conhecimento através da vida daqueles com os quais era obrigado a viver nas habitações coletivas. Logo cedo, em contato com a realidade, eu senti que fora equipado com as vestes de um cavaleiro andante para rastejar num pântano. Começou então a dolorosa mutilação moral. Eu representava na vida diária como em um palco, apressado que fiquei de ser semelhante àqueles que estavam ao meu lado. E tive que construir por cima de mim um homem grosseiro e banal, mas adaptado ao meio. (Furtado, 2019, p.80)

Assim, as experiências de mutilação moral, descolamento do grupo, derrocada individualista e refúgio nas artes que tece Furtado para as personagens refletiam aspectos de sua própria transumância em direção à capital e dos conflitos por ela suscitados. Nos anos 1990, quando indagado sobre seus esboços de romance, ele responde que

[...] grande parte dos chamados romancistas e que não são autênticos romancistas, são autobiográficos. De modo que todos os meus projetos no fundo versavam sobre experiências minhas. Essa é que é a história. E é aí que você vê a sua limitação como romancista. Para pintar uma sociedade, como romancista, como fez Proust é preciso um talento ou um gênio, natureza que eu não tinha. Se eu tivesse, não tinha ido para a Economia. (Furtado, 1992)

O fato de que escrevesse a partir da própria experiência era, pois, interpretado por ele como efeito de sua falta de talento e genialidade literária. Percepção que colabora para sabotar o desenvolvimento de seus projetos de romance. No caso, em junho de 1944, Furtado (2019, p.70) explica passar por uma crise de ataraxia e diz estar "agoniado com inutilidade do esforço, com a estupidez do resultado". O projeto de romance é então abandonado. Em setembro de 1945, no navio que regressava da Europa após a sua participação na Segunda Guerra Mundial, Furtado registra acreditar "que a ficção é um dos melhores meios de abordar certos problemas humanos que me apaixonam". Ele vocaliza, entretanto, alimentar dúvidas quanto ao seu talento literário e expressa ter também "vontade de me dedicar ao estudo de certos assuntos - Política, Administração, Ciências Sociais - e sobre eles escrever" (ibidem, p.95). 
Em 1946, a orientação para a escrita voltada às ciências humanas, aventada pouco antes, se concretiza. Furtado ingressa no doutorado em direito e ciências econômicas na Universidade de Paris - Sorbonne e cursa disciplinas no Instituto de Ciências Políticas. No período, consagra-se, dentre outras coisas, à leitura sistemática da obra de Karl Marx e dos marxistas, aos estudos sobre o entroncamento de economia e política, a partir das aulas de François Perroux, e à redação de uma tese sobre a Economia colonial brasileira, sob a direção do historiador econômico Maurice Byé (Furtado, 2014). Findo o doutorado, em 1948, regressa ao Brasil e, além de retomar seu trabalho no Dasp, incorpora-se à redação da revista Conjuntura Econômica, concentrando sua produção escrita no debate especializado em economia.

A década que separa o primeiro projeto de romance (1944) do segundo (1955) contempla, igualmente, o período no qual Furtado atuou como funcionário da Cepal. Como economista da Comissão, ele acompanhou a elaboração das formulações de Raúl Prebisch (2011) acerca das desigualdades de desenvolvimento decorrentes da disparidade estrutural das condições de inserção econômica da periferia no sistema internacional de trocas. Consequentemente, enquanto subsistisse a atual divisão internacional do trabalho e se defendesse o livre comércio e não intervenção econômica, a renda continuaria a se acumular no centro e as diferenças acentuadas nos níveis de vida no centro e na periferia permaneceriam inalteradas. A ciência econômica vista a partir da Cepal clamava, assim, por um engajamento dos estados e de seus economistas na promoção ativa do desenvolvimento e da transformação social, tarefas às quais Furtado dedicar-se-ia com afinco pelo resto de sua vida.

Como funcionário da Comissão, Furtado teve a oportunidade de aprofundar seus conhecimentos relativos aos países da América Latina e reconhecer as especificidades da economia, sociedade e política brasileira por comparação e contraste. Em 1953, Furtado fora designado pela Comissão para chefiar o Grupo Misto Cepal-BNDE, encarregado da elaboração de um conjunto de diagnósticos relativos ao funcionamento da economia brasileira com o objetivo de subsidiar a elaboração e implementação de um plano sistemático de desenvolvimento econômico para o país (Cepal-BNDE, 1957). A empreitada permitiu que Furtado se debruçasse sobre a dinâmica econômica e a realidade social brasileira e revisse seu país à luz dos conhecimentos acumulados no exterior.

Os estudos de economia e ciências sociais e a atuação como economista têm afinidades com mudanças na estrutura delineada para a ficção. No segundo projeto de romance, a narrativa é menos orientada ao desvelar do mundo íntimo e formação subjetiva das personagens. Em contraste, a trama passa a figurar em um contexto social e político conflitivo, marcado por desigualdades ligadas à origem de classe das personagens. Assim, as leituras sobre história do Brasil, às quais Furtado se dedicava com afinco, a observação das contradições entre classes sociais, presentes nos escritos marxistas, e as relações entre economia e política, tematizadas nos seus cursos de ciências sociais, deixam marcas no 
esboço literário de 1955. Nesse sentido, se a dedicação à escrita científica não rivalizava com o cultivo da paixão literária, ela transformava a perspectiva sobre os indivíduos e a sociedade presente em seu projeto de romance.

\section{$O$ retrato das estruturas sociais e do processo de tomada de consciência política no esboço de romance de $\mathbf{1 9 5 5}$}

Ao iniciar um novo desenho de romance, em novembro de 1955, na cidade de Paris, Celso Furtado (2019, p.141) indica que o objetivo da novela seria "retratar - através de seus reflexos na maneira de pensar - as enormes transformações ocorridas no país em uma geração" e contrapor "o conflito entre os ideais sociais e os atavismos individualistas, e o conflito entre os ideais individualistas e a estrutura social". Em comparação com o projeto de 1944, observa-se que o esboço tem um enquadramento histórico e social claro. Não se trata de um retrato intimista de agentes e de seus percursos individuais, mas do enfoque em uma geração e da observação dos indivíduos e de suas ações e ideais a partir do contexto e estrutura social no qual se inserem.

Furtado delineia uma narrativa baseada no contraste de duas personagens com origens sociais e posições de classe distintas. "O primeiro desses personagens é filho de uma família rica urbana; o segundo é filho de uma doméstica dessa mesma família" (ibidem, p.142). A história correria na Paraíba e teria início nos anos 1930, abordando fatos concernentes ao assassinato do governador e candidato a vice-presidente do Brasil na chapa de Getulio Vargas, João Pessoa Cavalcanti de Albuquerque. As posições sociais das famílias das duas personagens estariam associadas a tomadas de posição políticas contrastantes, em razão dos interesses de conservação ou de transformação da ordem social. No caso, não se tratava de transmutações do indivíduo e de sua moral calcadas nas experiências individuais, mas de visões de mundo ancoradas nas experiências de classes situadas em contexto histórico e político específico. Tal conformação guarda ressonâncias com as densas leituras marxistas que Furtado cultivou no período, bem como afinidades com o olhar estruturalista acerca da distribuição desigual de recursos e poder que carregou das aulas de Perroux e de seu trabalho na Cepal.

Furtado rabisca um primeiro diálogo entre as duas personagens, no qual o filho da empregada viria avisar o filho do patrão que seria necessário fugir, pois a casa de sua família seria incendiada como represália ao assassinato de João Pessoa. A primeira interação entre os dois é costurada de modo a revelar a hierarquia que os separa. Na cena, o filho da doméstica - que ele indica ser extremamente magro - entra na casa pela porta dos fundos e guarda uma distância cerimoniosa em relação ao jovem abastado, mobilizando pronomes de tratamento formais. Eles dormem na esteira de palha da casa dos domésticos, comem apenas um pedaço de pão e tomam café antes de partir para o refúgio da família rica (ibidem, p.142-3, 146).

Apesar de delinear um romance realista fundado na contraposição entre estratos sociais, Furtado não retrata as classes de maneira mecânica e estanque, 
atentando para as relações de dependência e para o caráter específico das interações entre elas no contexto brasileiro. Nesse sentido, o olhar antropológico sobre a cultura, que diz ter aprendido de Gilberto Freyre, ${ }^{8}$ contribuía para correlacionar a estrutura política às especificidades dos arranjos patriarcais, ao autoritarismo, à problemática racial e legados da escravidão que caracterizavam a sociedade nordestina.

A aproximação entre os dois personagens, provocada pelo incêndio, permite que o jovem da família abastada conheça as opiniões políticas dos empregados, com as quais nunca tinha tido contato. Ele escuta a mãe de seu interlocutor defender ardorosamente João Pessoa e falar dele como um milagreiro. A narrativa ecoa a própria experiência de Furtado que comenta, em texto autobiográfico, ter ouvido

[...] crédulo, das domésticas de minha casa, as histórias desse homem que se disfarçava "numa pessoa qualquer" para praticar o bem nos bairros mais humildes. O assassínio brutal desse homem (exatamente no dia em que eu completava os meus dez anos) provocou uma tal angústia coletiva que ainda hoje não posso me recordar sem me emocionar. Várias vezes acompanhei aquelas domésticas em longas procissões pelas ruas da cidade, seguindo um andor sobre o qual ia uma fotografia de João Pessoa de corpo inteiro. Creio que no espírito do povo havia mais tristeza do que revolta. A perplexidade diante de forças que pairam por cima de tudo e uma resignação que raia ao masoquismo e se traduz na frase "alegria de pobre não pode durar". (Furtado, 2013, p.32)

Furtado destaca a tendência de escapar, por meio da crença no sobrenatural, da brutalidade e incerteza de um Nordeste marcado por desigualdade, secas, autoritarismo e violência. João Pessoa era encarado, assim, não como mero chefe político, mas como portador de transformações sociais que resultariam, forçosamente, de um milagre. A injustiça não era vista, pois, como resultado de uma estrutura desigual que devesse ser ativamente transformada. Ao contrário, havia uma passividade e conformismo em relação à separação entre ricos e pobres que Furtado ilustra ao postular que:

A [o filho da família rica] imagina intimamente que B [o filho da doméstica] lhe deve ter um certo rancor, ou pelo menos inveja, e por isso é que está sempre retraído. B em realidade tem uma profunda consciência do desnível que existe entre os mundos em que os dois vivem. Mas daí não resulta nenhum rancor, seja porque o seu caráter é fundamentalmente infenso ao ódio, seja porque no mundo em que se criou the ensinaram a respeitar a riqueza e a considerar a pobreza como um mal natural. Algo assim como a cegueira: que prejudica em todos os momentos e deforma a alma daqueles que a têm. (Furtado, 2019, p.43)

Após a fuga, o jovem abastado abriga-se na fazenda herdada do avô materno, onde estava escondida toda a família. Nesse momento, delineiam-se as ideologias dos funcionários públicos de classe média que compunham o ramo 
materno. "Essa gente para quem o mundo terminava no outro lado da rua. A aceitação da ordem instituída como uma ordem natural. A inveja da riqueza. $\mathrm{O}$ respeito ilimitado por tudo que era autoridade. O complexo de inferioridade diante dos ricos refletindo-se num profundo desprezo pelo povinho e numa nítida consciência de classe social" (ibidem, p.143-4).

A família paterna, por sua vez, representaria as elites nordestinas provincianas do final da República Velha. No pai combinavam-se as figuras do herdeiro e proprietário de terras e a do advogado cujo bacharelado rendia provimentos materiais e simbólicos. Ancorado em seus compêndios jurídicos, o pai bradaria pela civilização contra a barbárie, acusando a revolta popular de ser o "triunfo da ralé ignorante" e João Pessoa de afrontar o reinado do direito. Furtado anota que o propósito da alternação entre a descrição da família abastada e de suas ideias cultivadas e a observação da condição da família empregada seria “deixar transparecer sutilmente a contradição entre o que pensam os que 'pensam' e a realidade corrente que os circunda" (ibidem, p.146).

Nesse caso, a descrição da família abastada evocava o próprio meio social de Furtado, formado por magistrados, funcionários públicos e detentores de terra. Ao longo do esboço, ele retrata a distância que tinha em relação a seu próprio pai, indica a reverência desse em relação ao direito, menciona o lugar da biblioteca na casa e discute o provincianismo das ideias que os circundavam. $\mathrm{O}$ encontro da personagem com a alteridade representada pelo mundo dos domésticos e a observação da extrema pobreza circundante suscitam um processo de tomada de consciência social. Tais experiências espelham vivências que Furtado diz estarem na base das "ideias-força, que enquadram meu comportamento na ação e também minha atividade intelectual criadora", inclusive da visão de que "a arbitrariedade e a violência tendem a dominar no mundo dos homens" e de que "a luta contra esse estado de coisas exige algo mais que simples esquemas racionais" (Furtado, 2013, p.32).

A parte seguinte do romance, rascunhada em dezembro de 1955, momento em que Furtado assumira uma missão como consultor da Cepal no México, versaria precisamente sobre o processo de tomada de consciência e luta como caminho para a transformação do estado das coisas. A segunda parte descreveria eventos transcorridos entre 1930 e a metade da década, desembocando no levante comunista de 1935 - que teve início precisamente no Nordeste. O propósito da narrativa seria, explica ele,

[...] demonstrar como num mundo pobre, com uma tremenda desigualdade na distribuição de renda, e estagnado, pega a ideologia socialista. Entra com a mesma força transformadora, destrutivo-construtiva, que teve o cristianismo primitivo num mundo fundado na escravidão. Em contraste com a primeira parte, que é uma reconstituição da sociedade existente, a segunda representará a penetração das novas ideias nessa sociedade. A pobreza era considerada como um defeito de nascença. A maior vitória social era ascender de uma classe a outra. A atividade intelectual era principalmente 
uma forma de exibicionismo. Vai-se sutilmente deixando transparecer que a própria organização econômica cria a necessidade de aplicar improdutivamente a riqueza. A penetração da ideologia socialista nada tem que ver com transformações internas da sociedade. Apenas se pode dizer que ela corresponde a um estado de desilusão, cansaço entre certos grupos intelectuais, com a Revolução de 1930. Mas o importante é que essa ideologia precipita uma tomada de consciência. De um instante para outro o mundo se transfigura para muitas pessoas. É como se fosse um ato de graça. A pobreza já não é um defeito e sim o lado negativo da exploração do homem pelo homem. Tudo aquilo que antes se explicava como um complexo natural de raça, indolência indígena, clima esgotante, atraso nacional, passa a ser atribuído à organização social. (Furtado, 2019, p.147-8)

O trecho esclarece o quanto o seu projeto de literatura era indissociável de suas elucubrações sobre a história, a economia e a sociedade brasileiras. Por meio da narrativa, ele discorreria acerca das condições para a instauração de um processo de transformação social, temática que ressoava tanto seus estudos marxistas da década precedente quanto a ideia Cepalina de que o desenvolvimento não se faria sem engajamento ativo. A tese de que "a própria organização econômica cria a necessidade de aplicar improdutivamente a riqueza", por exemplo, é desenvolvida por Furtado quando ele defende que a ideia de laissez-faire não é aplicável aos países subdesenvolvidos, posto que o baixo crescimento desses era devido sobretudo a inadequada orientação do investimento, já que esse era direcionado para o consumo de luxo ou para a importação, não criando emprego ou ajudando a aprimorar a estrutura econômica (Furtado, 1962, p.88).

A trama que concebe para o romance de 1955 era, assim, realista, na medida em que busca retratar a miséria, a desigualdade, o autoritarismo e o atraso da região de onde provinha, e engajado, ao tematizar o processo de tomada de consciência que subjaz a luta pela transformação social. Nesse sentido, a travessia por meio da qual a personagem principal toma consciência da realidade conflitiva que a circunda, descobre ideias que clamavam por mudanças e contrapõe-se ao interesse de seu meio social na conservação da ordem e do status quo, representa a própria peregrinação intelectual de Celso Furtado. Ele ilustra, assim, a conformação da visão do Nordeste que alimentará sua produção como intelectual e do ethos que balizará suas ações como economista e figura pública.

Os breves rascunhos de Furtado para as partes seguintes do texto indicam que essas enfocariam cada indivíduo e o processo de formação do individualismo. O texto seria costurado a partir das experiências de translado para o Rio de Janeiro e para a Europa das personagens e pelo encontro delas com o mundo artístico, retomando temáticas presentes no primeiro projeto de romance. As anotações sobre o romance findam nesse ponto. Há apenas uma notícia sobre o avanço do projeto, que data de outubro de 1960, quando Furtado menciona ter relido as cinquenta páginas do romance escritas em 1957, em Caracas, e diz que gostaria de ter tempo para retomá-lo. O que diz não ser possível, posto 
estar envolvido com a elaboração de um livro de ensaios teóricos e outro sobre desenvolvimento, além do trabalho na Sudene (Furtado, 2019, p.163, 227). O último projeto literário mencionado nos Diários data de 1975 e foi concebido durante o exílio de Furtado na França. A história trataria precisamente da experiência de um professor exilado, encarregado da orientação de uma tese que acabaria por versar sobre a derrocada das ilusões quixotescas de transformação social alimentadas pela geração do professor (ibidem, p.274-5).

\section{Do literato ao economista}

Se é possível argumentar que a formação científica teve impactos sobre o desenho do romance de Celso Furtado, é igualmente plausível sustentar que as lentes de literato, cultivadas desde a juventude, apuraram sua visão sobre a economia e a sociedade brasileiras. Ao falar de sua relação com a economia, Furtado (2013, p.39) explica que ela "não chegaria a ser para mim mais que um instrumental, que me permitia, com maior eficácia, tratar problemas que me vinham da observação da história ou da vida dos homens em sociedade. Pouca influência teve na conformação do meu espírito. Nunca pude compreender a existência de um problema estritamente econômico". Nesse sentido, as incursões na economia e na literatura desempenhavam, no fundo, papel similar, a saber, o aprofundamento do conhecimento sobre a vida social e o próprio país. Furtado fazia, ademais, ressalvas em relação à divisão estrita entre ciência e ficção, argumentando que

[...] as Ciências Sociais são em grande parte obras de ficção escritas de forma codificada por conveniência dos que a praticam. As proposições que elas formulam dificilmente são verificáveis. [...]. É a capacidade de influenciar os espíritos que, no caso, intervém. Mais precisamente: veja-se a nova teoria monetária; nenhuma das proposições formuladas por [Milton] Friedman é passível de verificação. Isso permite que ele seja usado como material para alimentar o debate ideológico. (Furtado, 2019, p.276)

Formulações supostamente científicas, como as da teoria monetária, seriam, ademais, potencialmente perniciosas, ao apresentar suas ficções como leis neutras e universais nas quais deveriam basear-se as decisões econômicas de políticos e especialistas. ${ }^{9} \mathrm{O}$ romance realista e engajado, ao contrário, trata a realidade de maneira declaradamente ficcional, colaborando para influenciar o espírito dos leitores sem clamar serem científicas suas teses sobre a vida social. Furtado (1992) argumenta que o "instrumento do romance da ficção era a melhor forma de pintar o homem", e não a ciência. O romancista, ao observar a dimensão subjetiva e retratar o impacto das estruturas sociais sobre as trajetórias, dificilmente pintaria um homem abstrato e desenraizado como o "bomo oxconomicus, em cuja psicologia rudimentar os clássicos pretenderam assentar as leis econômicas fundamentais" (Furtado, 2009, p.159).

A análise do projeto de romance de 1955 permite postular que o indivíduo sobre o qual se debruçava Furtado não era isolável e não tinha preferências 

abstratas e imutáveis como o homo oxconomicus. Ele estava rodeado de crenças e ideologias cambiantes. Partilhava de culturas regionais específicas. Vivia contextos históricos particulares e posicionava-se ante a ordem social e a política. Suas aspirações se formavam em suas classes sociais de origem, mas podiam transformar-se ao longo do tempo, em razão das relações tecidas pelos agentes e do contexto político. Assim, o retrato que urdia por meio da literatura considerava, concomitantemente, os níveis macro e intermediário de análise social, contemplando tanto a tendência de reprodução das estruturas quanto as mudanças aportadas pelas interações sociais e reconhecimento da alteridade. $\mathrm{O}$ indivíduo para Furtado se fazia, assim, histórica e contextualmente, não podendo a sua ação ser interpretada como um ato racional de consumo voltado à maximização do bem-estar individual; tal qual supunham os modelos econômicos neoclássicos.

A heterodoxia na economia contesta, precisamente, o uso que os neoclássicos fazem do individualismo metodológico, "o caráter exógeno e estático dos pressupostos psicológicos e sociológicos e [...] a negligência dos fatores históricos e dinâmicos"10 na análise econômica. Os heterodoxos consideram que os arranjos econômicos variam de acordo com as culturas e prioridades políticas, o que exige que os estudos sejam localizados e empíricos, ao invés de ater-se ao desenvolvimento de modelos gerais baseados em pressupostos predeterminados sobre o comportamento humano (Rotschield, 1989 , p.4). Economistas heterodoxos buscam, portanto, desenvolver novas teorias adequadas aos fenômenos sociais e históricos que observam, questionando, a partir da empiria, a universalidade das teorias pré-existentes (Bresser-Pereira, 2004, p.23).

Celso Furtado e Robert Woodward.

Departamento de Estado, Washington D.C., 1961. 
Metodologicamente, tanto a ciência econômica quanto a literatura praticada por Furtado eram calcadas em observações históricas e atentas às estruturas sociais. Ao enquadrar os indivíduos e suas decisões em classes sociais e contextos políticos particulares e ao voltar sua ciência econômica ao estudo da especificidade histórica, econômica, social e cultural do subdesenvolvimento, Furtado convertia-se em um economista inexoravelmente heterodoxo. Seu método científico passava, ademais, pelo exercício literário que consistia em imaginar e inventar o mundo social antes de tecer hipóteses sobre o seu funcionamento. Furtado esclarece que

[...] a descoberta que faço do homem é através da literatura, nunca pela ciência. As Ciências Sociais são métodos de reduzir e o homem só se capta totalmente. E é preciso inventá-lo. [...]. É o rigor do método, a necessidade de se submeter a provas de erros para, finalmente, formalizar a realidade, colocá-la numa linguagem matemática, o que vai empobrecê-la totalmente. [A análise...] exige imaginação, disciplinada, é claro, para resultar em hipóteses globais. Meu método sempre foi esse, globalizar pela imaginação, (Furtado, 2012, p.198)

A imaginação disciplinada de Celso Furtado pode ser entendida como uma imaginação sociológica, na acepção de Wright Mills (1982, p.11-12), na medida em que "capacita seu possuidor a compreender o cenário histórico mais amplo, em termos de seu significado para a vida íntima e para a carreira exterior de numerosos indivíduos". Seus escritos literários complementam as suas análises estruturalistas ao retratar como, dentro do cenário das grandes transformações históricas, as especificidades culturais e as relações sociais contribuem para moldar as biografias e desenvolvimentos subjetivos. Mills indica justamente que os romancistas possuem com frequência essa imaginação sociológica e contribuiriam para o "entendimento das realidades íntimas de nós mesmos em ligação com realidades sociais mais amplas" (ibidem, p.22).

Para Furtado, compreender a realidade íntima de si mesmo no cenário social que o circundava esteve sempre no cerne de suas explorações como economista e literato. Conhecer e compreender para então agir no sentido de transformar o mundo que o cercava. Não é fortuito que a literatura praticada por Furtado fosse autobiográfica e que o fulcro de suas inquietações como economista e homem público fosse o Nordeste. Furtado (2013, p.41) indaga diretamente se seu

[...] desejo insaciável de penetrar na realidade do próprio país não encobre outro desejo ainda mais fundamental: o de conhecer-se a si mesmo. Como superar as limitações do quadro psicológico pessoal sem penetrar nas condicionantes sociais e culturais? Até que ponto meu interesse pelo Nordeste decorre de uma simpatia profunda pelo mundo que mais conheço (o de minha infância e adolescência) ou reflete principalmente a consciência que tenho de que sou prisioneiro das estruturas sociais em que me formei, mesmo quando contra elas me revolto? 
Jonas Rama e John Bataille Hall (2019, p.661) argumentam o fator que permitiu que Furtado "rompesse com os constrangimentos encontrados na academia e adotasse uma abordagem nova, imaginativa e criativa" da economia foi, precisamente, o engajamento e identificação pessoal com a temática do sertão nordestino. A miséria, a violência, a seca e o autoritarismo que ele conheceu no Nordeste e retratou em sua literatura e ciência não podiam ser entendidos a partir do ferramental da economia neoclássica. Melhorar as condições de vida da população nordestina requeria conhecer; e para conhecer e forjar ferramentas para intervenção Furtado precisaria enxergar as especificidades da sociedade, da cultura e da política nordestina e tecer teorias originais e imaginativas que dissessem sobre as condições para o desenvolvimento dadas tais especificidades. Economia, história e literatura convergiam e combinavam-se, assim, para aprimorar a compreensão que tinha do Brasil, do Nordeste, de sua geração e de si.

\section{Conclusão}

Celso Furtado consagrou-se como economista e homem público e não como o romancista que imaginaria ter sido em sua juventude. Sua afinidade com a literatura esteve, no entanto, sempre presente em sua trajetória, tendo colaborado para moldar a forma como imaginava a sociedade e tecia suas hipóteses analíticas. Nesse sentido, a imaginação do romancista, vista por Eugênio Gudin como um desvio do rigor da análise econômica, esteve no cerne da produção de Furtado como economista heterodoxo. Literatura e economia convergiam para apurar a leitura sobre as especificidades culturais e políticas, para destacar a dimensão estrutural dos problemas do subdesenvolvimento e para prepará-lo para agir como figura pública imbuída da busca de soluções singulares para os problemas econômicos e sociais nacionais e regionais. Assim, ainda que a contribuição literária de Celso Furtado não tenha lugar de destaque em seu legado, o olhar literário, constantemente exercitado, foi fundamental para o cultivo da imaginação como método analítico e para a formação de uma visão interdisciplinar e historicamente enraizada de economia e sociedade brasileira.

\section{Notas}

1 Agradeço a Alexandre Barbosa de Freitas por apontar a beleza dos projetos literários de Celso Furtado, e a Rosa Freire d'Aguiar pelo envio de materiais e pelas informações detalhadas sobre o contexto da escrita dos romances e sobre práticas de leitura de Furtado.

2 As correntes mainstream no tempo de Furtado podem ser definidas como neoclássicas. Essas focam na alocação de recursos escassos em um ponto do tempo entre finalidades alternativas. As escolhas são feitas por indivíduos com preferências dadas e racionalidade voltada à maximização da utilidade e otimização do ganho. A racionalidade individual é empregada em situações de trade off que configuram a demanda constitutiva do mercado e, consequentemente, da economia (Colander, 2000, p.134-5).

3 Eugênio Gudin foi um dos primeiros brasileiros a dedicar-se de maneira sistemática ao ensino e pesquisa em economia; e era conhecido por suas firmes convicções liberais. 
Ele fundou, em 1946, duas das grandes escolas de economia do Rio de Janeiro, a Fundação Getulio Vargas e a Faculdade Nacional de Ciências Econômicas, e foi Ministro da Fazenda entre 1954 e 1955.

4 Seus escritos foram reunidos por sua esposa, Maria Alice Furtado, no volume Coisas do Passado. Paraíba: Instituto Histórico Paraibano, 1970. Disponível em: <http://www. ihgp.net/mauricio.htm>. Acesso em: 27 set. 2020.

5 Rosa Freire d'Aguiar é jornalista, tradutora e editora. Foi responsável pela organização da Coleção "Arquivos Celso Furtado", dos Diários intermitentes e do compêndio de cartas de Celso Furtado, em vias de publicação, além de presidir o Conselho Deliberativo do Centro Celso Furtado. As informações mencionadas foram transmitidas por Rosa d'Aguiar em conversa por Zoom, em 26 agosto de 2020.

6 A lapinha, ou dança pastoril formada pelos cordões azul e encarnado, era integrada por dançarinas trajando fantasias das respectivas cores. A dança integra o repertório religioso natalino na cidade de João Pessoa e consiste na encenação de um contraponto entre os dois cordões, que representam o coração de Jesus e Maria ou a luta entre cristãos e mouros. A dança comporta ainda uma competição entre os cordões voltada à arrecadação de fundos para as igrejas e paróquias da região (Bezerra, 2013).

7 Em diversas ocasiões Furtado registra em seus diários o que estava lendo. Em 1937 1938, por exemplo, menciona ter lido "Oguarani, J. de Alencar, Diva, J. de Alencar, Casa-grande \& senzala, G. Freyre, Memórias póstumas de Brás Cubas, M. de Assis, Quincas Borba, M. de Assis, Joseph Fouché, S. Zweig”. Discorrerá, em outros momentos, sobre A Montanha Mágica, de Thomas Mann, menciona a influência da Condição Humana, de André Malraux, e comenta conversa com Guimarães Rosa sobre os problemas da tradução (Furtado, 2019, p.50-1, 69, 130-1, 174).

8 Gilberto Freyre fez parte das leituras precoces de Furtado. Ainda que a interpretação da colonização e formação do capitalismo brasileiro presente em Casa grande é senzala (1933) seja diretamente confrontada por Furtado em sua tese de doutorado (Silva, 2010), o olhar de Freyre sobre o Nordeste e, sobretudo, o enquadramento antropológico da cultura são mencionados por Furtado como influências importantes na formação de seu pensamento sobre o Nordeste (Furtado, 2013, p.34).

9 Temática que Furtado discute em seus escritos sobre a ciência econômica, por exemplo ao queixar-se da inadequação das exigências que o Fundo Monetário Internacional fazia a países da periferia. Ver Klüger (no prelo).

10 Em suas recomendações sobre a formação de economistas para atuar na periferia, Furtado ressaltava precisamente a necessidade de desenvolver uma ciência econômica que fosse afinada com as outras ciências sociais e com a história, com o objetivo de enxergar as especificidades das estruturas sociais, culturas e contextos históricos e políticos nos quais transcorre a vida econômica (Furtado, 1962a, p.55).

\section{Referências}

BEZERRA, A. S. Lapinha: a dança como linguagem corporal no contexto religioso. João Pessoa, 2013. Dissertação (Mestrado em Ciência das Religiões) - Universidade Federal da Paraíba.

BRESSER-PEREIRA, L. C. Method and Passion in Celso Furtado. CEPAL Review, n.84, p.19-34, 2004. 
CEPAL-BNDE. Esboço de um programa de desenvolvimento para a economia brasileira: 1955-1962. Rio de Janeiro: Cepal-BNDE, 1957.

COLANDER, D. The Death of Neoclassical Economics. Journal of the History of Economic Thought, v.22, n.2, p.127-43, 2000.

FURTADO, C. A objetividade do economista. In: A pré-revolução Brasileira. Rio de Janeiro: Fundo de Cultura, 1962.

Notas sobre o projeto de criação de uma escola de economia para pós-graduados na América Latina. Econômica Brasileira, v.8 n.1, p. 51-56, 1962 a.

Entrevista à Amir Labaki e Gilson Schwartz. Folha Mais. São Paulo, 19 de julho de 1992. Disponível em: <https://wwwl.folha.uol.com.br/fsp/especial/mais/ historia/190792.htm>. Acesso em: 27 set. 2020.

Desenvolvimento e subdesenvolvimento. Rio de Janeiro: Contraponto, 2009.

A síntese segundo Celso Furtado: Entrevista a Gabriela Marinho. In: D’AGUIAR, R. F. (Org.). Ensaios sobre cultura e o Ministério da Cultura Rio de Janeiro: Contraponto, 2012. (Col. Arquivos Celso Furtado, v.5)

Aventuras de um economista Brasileiro. In: D’AGUIAR, R. F. Essencial Celso Furtado. São Paulo: Penguin Classics Cia. das Letras, 2013.

Obra autobiográfica: A Fantasia Organizada, A Fantasia Desfeita, Os Ares do Mundo. São Paulo: Cia. das Letras, 2014.

Diários intermitentes: 1937-2002. São Paulo: Cia. das Letras, 2019.

GUIMARÃES, J. I. D. Entre a rotina e a quimera: jogo literário e política na Belo Horizonte dos anos 20. São Paulo, 2017. Tese (Doutorado em Sociologia) - Faculdade de Filosofia Ciências e Letras, Universidade de São Paulo.

KLÜGER, E. Celso Furtado: por uma Ciência Econômica iconoclasta e inconformista. No prelo.

MICELI, S. Intelectuais à brasileira. São Paulo: Cia. das Letras, 2001.

MILLS, C. W. A imaginação sociológica. Rio de Janeiro: Zahar, 1982.

PREBISCH, R. O desenvolvimento econômico da América Latina e alguns de seus problemas principais. In: GURRIERI, A. O Manifesto Latino-Americano e outros ensaios. Rio de Janeiro: Contraponto, 2011.

RAMA, J.; HALL, J. B. Celso Furtado as 'Romantic Economist' from Brazil's Sertão. Brazilian Journal of Political Economy, v.39, n.4, p.658-74, 2019.

ROTSCHIELD, K. Political Economy or Economics? European Journal of Political Economy, n.5, p.1-12, 1989.

SILVA, R. P. O jovem Celso Furtado: história, política e economia (1941-1948). Campinas, 2010. Dissertação (Mestrado em Economia) - Instituto de Economia, Universidade Estadual Paulista.

RESUMO: Este ensaio tematiza a afinidades entre a prática literária de Celso Furtado e sua perspectiva analítica como economista. Conforme revelam sua autobiografia, seus diários e entrevistas, a paixão e os flertes com a literatura foram recorrentes e importantes 
em sua trajetória. É possível argumentar que a proximidade de Furtado com a literatura contribuiu para fazer dele um economista com uma sensibilidade para enredos povoados por indivíduos que em nada se aproximam do homo xconomicus da teoria econômica neoclássica e para cenários conformados por estruturas sociais, culturais e de poder que enquadram as ações desses indivíduos. Este ensaio enfoca o projeto de romance delineado por Celso Furtado em 1955 e registrado em seus Diários intermitentes 1937-2002 (2019). O texto é tomado como ponto de observação privilegiado para apreender a imaginação sociológica e a interpretação histórica e culturalmente enraizada da economia e sociedade brasileira que fizeram de Celso Furtado um economista inexoravelmente heterodoxo.

PALAVRAS-CHAVE: Celso Furtado, Literatura, Diários intermitentes, Imaginação sociológica, Ciência econômica.

ABSTRACT - This essay discusses the affinity between Celso Furtado's literary practice and his analytical perspective as an economist. As his autobiography, diaries, and interviews reveal, his passion and flirtations with literature were recurrent and important in his trajectory. It is possible to argue that Furtado's proximity to literature contributed to making him an economist sentient both to narratives inhabited by individuals who in no way resemble the homo xconomicus of neoclassical economic theory and to scenarios shaped by social, cultural, and power structures that frame the actions of those individuals. This essay focuses on the project of a novel outlined by Celso Furtado in 1955, and recorded in his Diários intermitentes 1937-2002 (2019). The text is examined as a privileged viewpoint to apprehend the sociological imagination and the historicallyand culturally-rooted interpretation of Brazilian economy and society that made Celso Furtado an inexorably heterodox economist.

KEYWORD: Celso Furtado, Literature, Diários intermitentes, Sociological imagination, Economics.

Elisa Klüger é doutora em Sociologia e graduada em Relações Internacionais na Universidade de São Paulo. Atualmente é pesquisadora de pós-doutorado no Centro Brasileiro de Análise e Planejamento e foi pesquisadora de pós-doutorado visitante associada na Universidade de Princeton, pela Fapesp, processos 2017/13937-1 e 2018/09487-7. @ - elisa.kluger@gmail.com / https://orcid.org/0000-0002-2375-8565.

Recebido em 29.9.2020 e aceito em 2.10.2020.

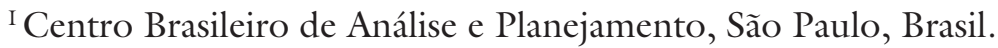

